\title{
The Probabilistic Analysis of the Possibilities to Keep “Organism Integrity” by Continuous Monitoring
}

\author{
Andrey Kostogryzov ${ }^{1,2, *}$, Andrey Nistratov ${ }^{3}$, George Nistratov ${ }^{4}$, Oleg Atakishchev ${ }^{2,5}$, Sergey Golovin ${ }^{6}$ and Leonid \\ Grigoriev $^{7}$ \\ ${ }^{1}$ Federal Research Center “Computer Science and Control” of the Russian Academy of Sciences, \\ Moscow, Russia \\ ${ }^{2}$ Main Scientific Research Test Center of the Russian Ministry of Defence, Moscow, Russia \\ ${ }^{3}$ The Russian Power Agency of Ministry for the Power Generating Industry, Moscow, Russia \\ ${ }^{4}$ The Research Institute of Applied Mathematics and Certification, Moscow, Russia \\ ${ }^{5}$ Southwest State University, Kursk, Russia \\ ${ }^{6}$ Moscow State Technical University of Radioengineering, Electronics and Automatics, Moscow, Russia \\ ${ }^{7}$ The Gubkin Russian State University of Oil and Gas, Moscow, Russia
}

\begin{abstract}
The approach to estimate the effectiveness of continuous monitoring of organism conditions is proposed. The probabilities to keep "acceptable integrity" of an organism for the given period of time "in future" are estimated in application of different life conditions. The results of the probabilistic analysis confirm quantitatively, that at the expense of continuous monitoring of organism conditions (including operative recovering of integrity to the acceptable level) a person in the near future can operate all life without any serious known diseases.
\end{abstract}

Keywords - analysis; diagnostic; healthcare; model; monitoring, probability; system; technology

\section{INTRODUCTION}

Today healthcare is supported by different technologies of periodic preventive diagnostics. On the market many special medical systems are used. They allow to carry out a qualitative and quantitative estimation of a functional condition of an organism, to establish a source of dangerous influences on health etc. Not going into detail of diagnosing experts and systems, we will notice only, that by results of periodic diagnostics the individual program of recovering health integrity of an organism is created. The person needs only accurately to carry out periodic diagnostics and, if needs, the recovering of integrity of an organism.

Other novelty of last years is the technology of monitoring based on diagnostic system with intellectual sources built in daily clothes, instantly informing about dangerous changes of human organism conditions. The easy portable computer performs processing of information gathered. It is original compulsory continuous monitoring of a health state of an organism between periodic diagnostics of organism integrity. Last years the system is actively used in sports medicine.

It is clear, that for general case continuous monitoring of organism conditions is more effective. But how much? Till now quantitative existing approaches use a principle "post factum”. For the development of existing approaches this work proposes the approach to compare the effectiveness of technologies of periodic diagnostics (technology 1) and continuous monitoring of conditions of an organism (technology 2). The approach is based on mathematical modeling of different processes with the probabilistic prediction answers on question "Is an acceptable organism integrity kept?" for the given period of time "in future". The answers define the possibilities to keep "organism integrity” by continuous monitoring.

\section{Choice of Probabilistic Model AND Metrics}

For probabilistic estimations of the technologies in application to given prognostic period "in future" the next limited space of two elementary events for an organism is set: "acceptable integrity is kept" (when from healthcare point of view no additional actions are needed to keep acceptable organism integrity) and "acceptable integrity is lost" (when some actions are needed for recovering acceptable integrity of organism).

Note. It is considered that the terms "organism integrity" and "acceptable integrity" are defined from healthcare point of view.

The probabilistic model "Protection against dangerous influences" [1-3], developed of authors of this work, is chosen. It allows estimate technology 1 (proactive diagnostic of system integrity) and more general technology 2 (security monitoring). After the next diagnostic the recovery of the lost integrity is started, if needed. The differ of technology 2 is the next: if results of monitoring have revealed symptoms of unacceptable health worsening, the recovery of the integrity is started before the beginning the next diagnostic.

The next metrics are used for probabilistic estimating organism conditions by the model "Protection against dangerous influences" [1-3]: the probability to keep "acceptable integrity" (if all time during this given prognostic period organism will be in elementary event "acceptable integrity is kept") and the probability to lose "acceptable integrity” (if at least once during this given period organism 
will be in elementary event "acceptable integrity is lost”) - as addition to 1 the probability to keep "acceptable integrity".

The input data for probabilistic estimating are [1-3]: the given prognostic period "in future"; the frequency of dangerous influences for penetrating into organism (defining the beginning of influencing); the mean activation time (when "acceptable integrity" may be lost" after beginning of influencing); the time between the end of diagnostic and the beginning of the next diagnostic; the diagnostic time; only for technology 2 - the mean time between doctor's error during continuous monitoring of organism integrity.

\section{THE CONDITIONS FOR MODELING}

At modelling natural ageing of a human body is not considered. Those threats to health which are known to medicine, traced at diagnostics and do not cause irreversible consequences at the first influence, are considered only. Besides, it is supposed, that the organism can be operatively recovered after medical intervention at the earliest stages of detection of dangerous or guarding symptoms. Moreover, at modeling the time of full integrity recovering is artificially reduced till diagnostic time. Thus, the elementary condition "acceptable integrity is kept" means absence of danger source or liquidation of a penetrated source at the earliest stage prior to the its danger influence on an organism (after activation time and transformation into condition "acceptable integrity is lost”).

Note. The above assumptions are supposed for modeling. In a reality it may be not always so. These conditions should be considered for interpretation of modeling results.

To define the possibilities to keep "organism integrity” by continuous monitoring we compare 3 typical models of patient behaviour in a life. Let's the threats to health of the person arise 1 time a day (as for the child). After occurrence of a danger source in an organism (for example, colds, infections, the uses of stale food, etc.) average activation time is equal to 6 hours, during which else it is possible to prevent or neutralize negative influence, i.e. to keep acceptable integrity of an organism.

Let's consider 3 variants of reaction of the person caring of health. $1^{\text {st }}$ variant (polyclinic) considers the address of the usual person in a polyclinic and reception of necessary recovering procedures within 4 hours after reception. $2^{\text {nd }}$ variant (doctor of the enterprise) assumes operative intervention of the doctor after detection of the first symptoms of danger and recovering acceptable integrity of an organism within one hour. For $3^{\text {rd }}$ variant ("in real time" - a variant of our near future) the patient uses operatively the personal electronic doctor (for example, embedded into a portable computer). This electronic doctor on a basis of stored data about health history of the patient, the actual information of current conditions forms in real time the recommendations about recovery of health integrity. The patient independently or by means of the doctor or other means performs these recommendations. All procedure of diagnostics and the subsequent regenerative actions occupies no more a quarter of hour. For all variants mean time between doctor's error during continuous monitoring of organism integrity is estimated not less than 1 year (for general technology 2). Initial input data for probabilistic modeling are reflected by the Table.
TABLE I. INPUT DATA FOR ESTIMATION

\begin{tabular}{|l|c|c|c|}
\hline \multirow{2}{*}{ Input } & \multicolumn{2}{|c|}{$\begin{array}{c}\text { Variants of person actions } \\
\text { for comparisons }\end{array}$} \\
\cline { 2 - 4 } & \multicolumn{1}{|c|}{$\begin{array}{c}\text { 1-nd } \\
\text { (doctor } \\
\text { of the } \\
\text { enter- } \\
\text { prise) }\end{array}$} & $\begin{array}{c}\text { 3-rd } \\
\text { ("in real } \\
\text { time”) }\end{array}$ \\
\hline $\begin{array}{l}\text { The given prognostic period "in } \\
\text { future" }\end{array}$ & 3 years & 5 years & 150 years \\
\hline $\begin{array}{l}\text { The frequency of influences for } \\
\text { penetrating into organism }\end{array}$ & 1 day-1 & 1 day ${ }^{-1}$ & 1 day $^{-1}$ \\
\hline The mean activation time & 6 hours & 6 hours & 6 hours \\
\hline $\begin{array}{l}\text { The time between the end of } \\
\text { diagnostic and the beginning of } \\
\text { the next diagnostic }\end{array}$ & 1 month & 4 hours & 1 min. \\
\hline The diagnostic time time between \\
\hline $\begin{array}{l}\text { The mean turing } \\
\text { operator's error } \\
\text { continuous monitoring of } \\
\text { organism integrity }\end{array}$ & 1 year & 1 year & 1 year \\
\hline
\end{tabular}

\section{ANALYSIS OF THE ESTIMATIONS}

Some dependences of probability to keep “acceptable integrity” from input data, changing in diapason $-50 \%+100 \%$ from the Table, are presented on Figures 1, 2, 3 for variants 1, 2 , 3. They cover dependences on the given prognostic period "in future", the time between the end of diagnostic and the beginning of the next diagnostic, the mean time between operator's error during continuous monitoring of organism integrity (deviations for other dependences are insignificant).
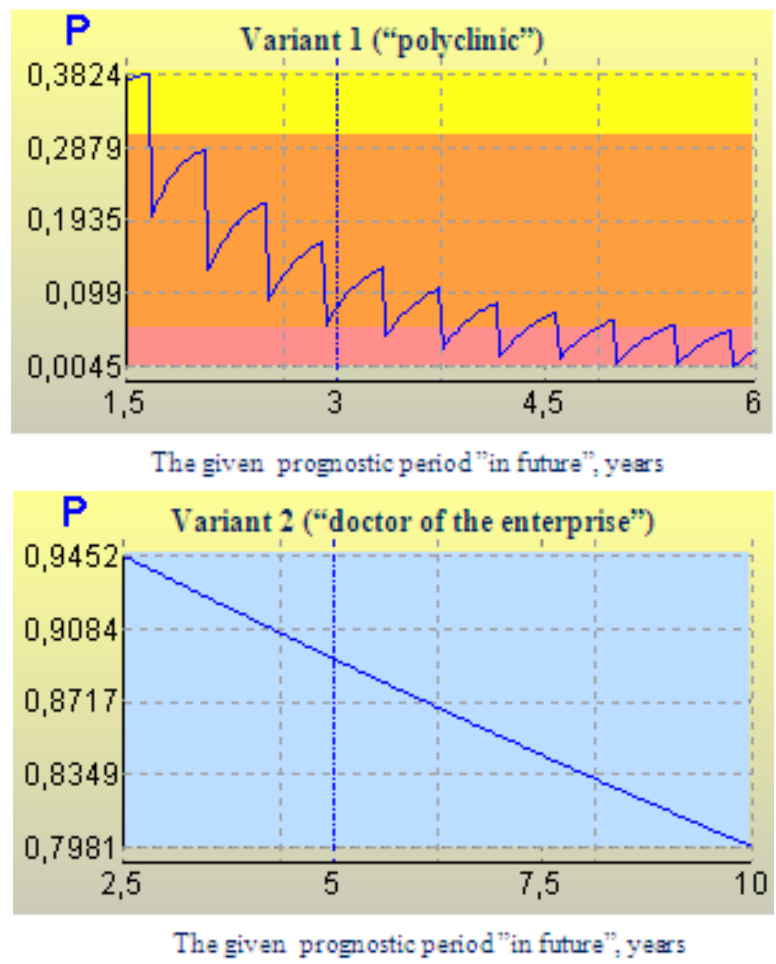


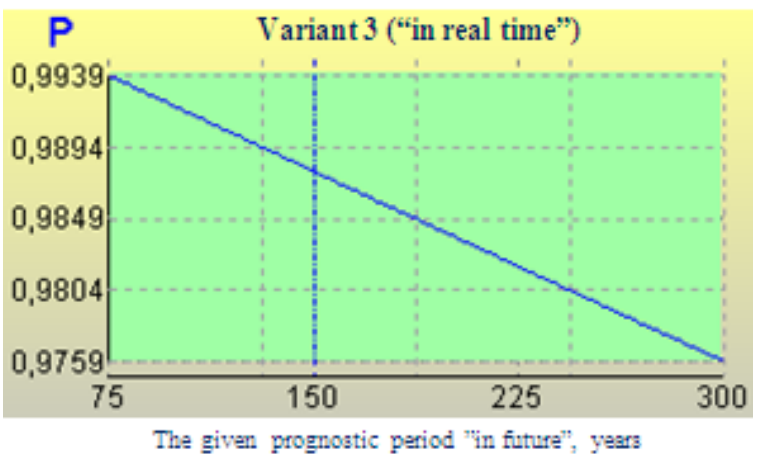

FIGURE I. DEPENDENCE OF PROBABILITY TO KEEP “ACCEPTABLE INTEGRITY” ON THE GIVEN PROGNOSTIC PERIOD
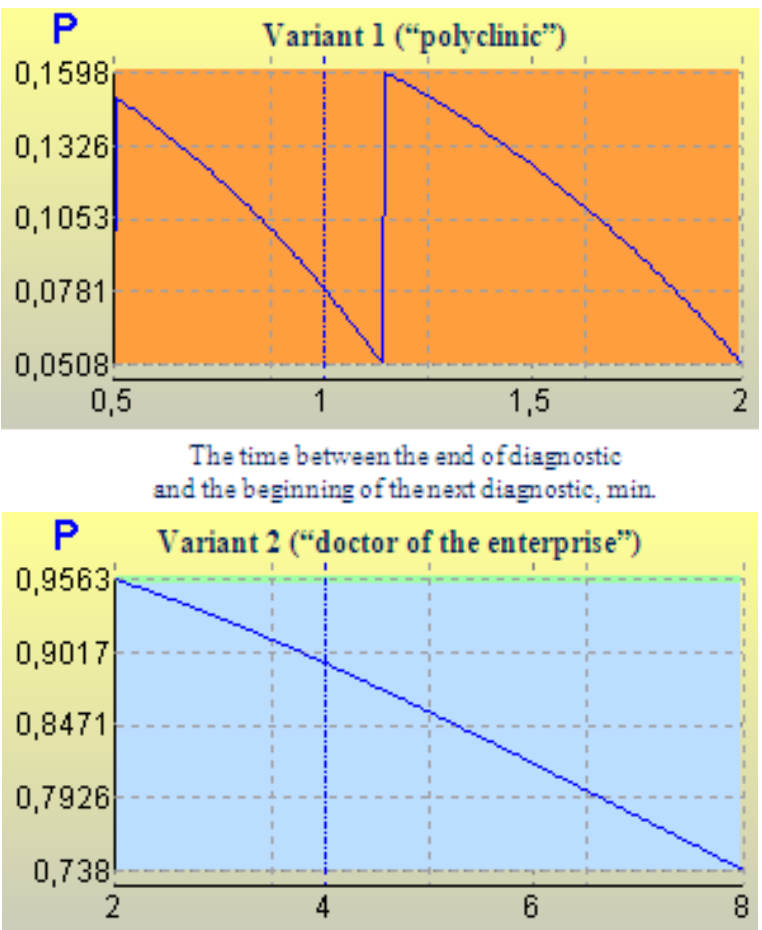

The time between the end of diagnostic and the beginning of the next diagnostic, month

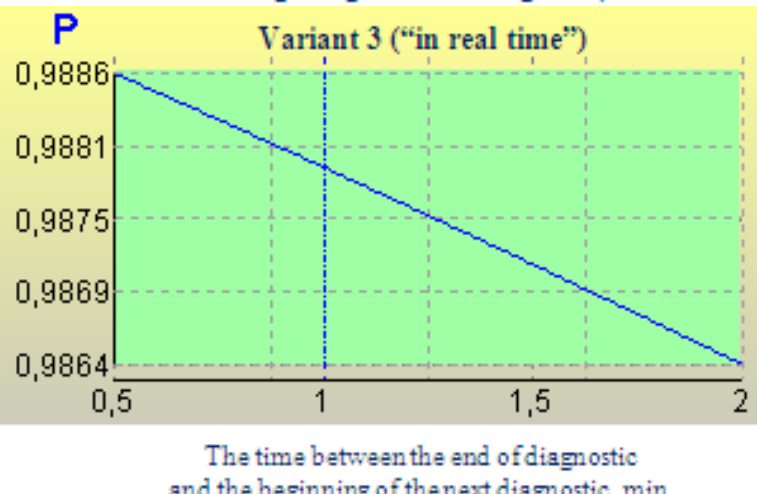

FIGURE II. DEPENDENCE OF PROBABILITY TO KEEP “ACCEPTABLE INTEGRITY" ON THE TIME BETWEEN THE END OF DIAGNOSTIC AND THE BEGINNING OF THE NEXT DIAGNOSTIC

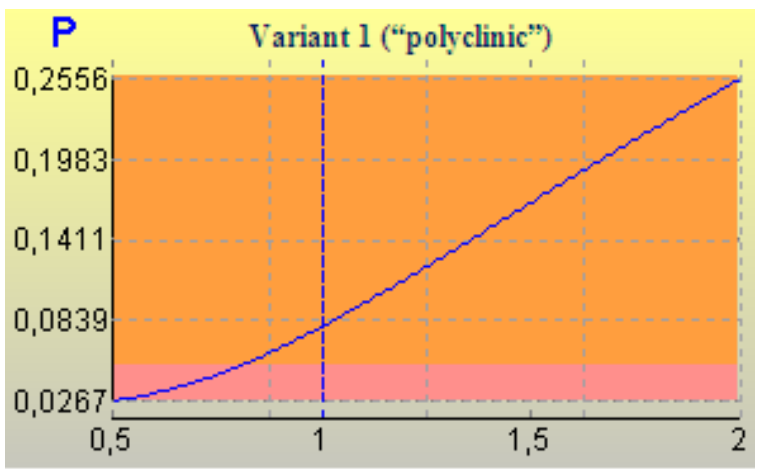

The mean time between operator's error during,

continuous monitoring of organism integrity, years

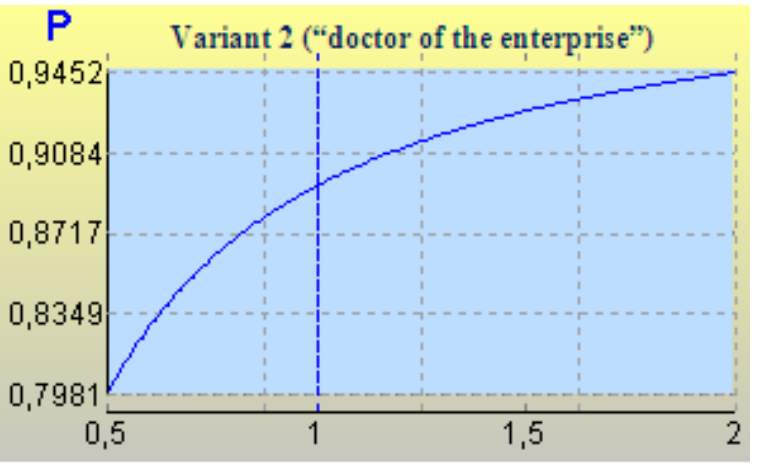

The mean time between operator's error during, continuous monitoring of organism integrity, years

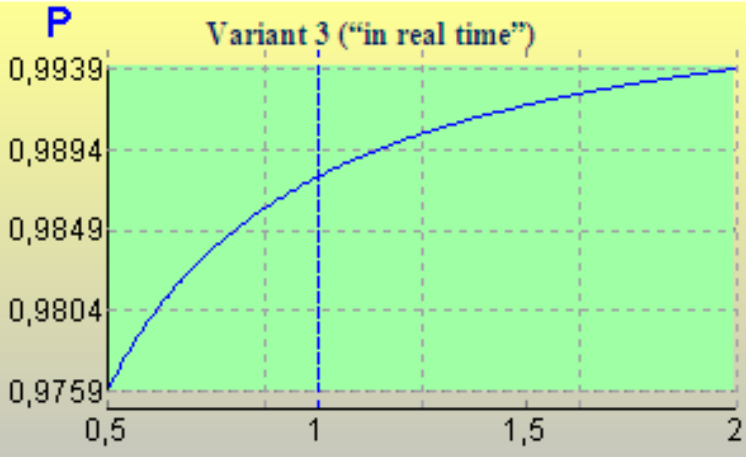

The mean time between operator's error during, continuous monitoring of organism integrity, years

FIGURE III. DEPENDENCE OF PROBABILITY TO KEEP

“ACCEPTABLE INTEGRITY” ON THE MEAN TIME BETWEEN OPERATOR'S ERROR DURING CONTINUOUS MONITORING OF ORGANISM INTEGRITY

Results of modeling show, that for $1^{\text {st }}$ variant (polyclinic) the probability to keep "acceptable integrity" during 1 year is equal to 0.39 , during 2 years - not less than 0.16 , during 3 years - only 0.07 . 2nd variant (doctor of the enterprise) with operative recovering is more effective. Really, it is possible to be healthy on "acceptable integrity level" within 3-5 years with probability about $0.90-0.93$. At last, the $3^{\text {rd }}$ variant of the healthy future when each person will possess the personal electronic doctor and possibility of reaction to health deviations «in real time», conceals in itself simply fantastic perspectives. Initially healthy, reasonable and punctual person with 
probability 0.99 and more can count on "acceptable integrity" of an organism during all life (more than 100 years)!

A stability of the summary is confirmed by the results on Figure 4 for input data (no covered by Figures 1-3), changing in diapason $-50 \%+100 \%$.
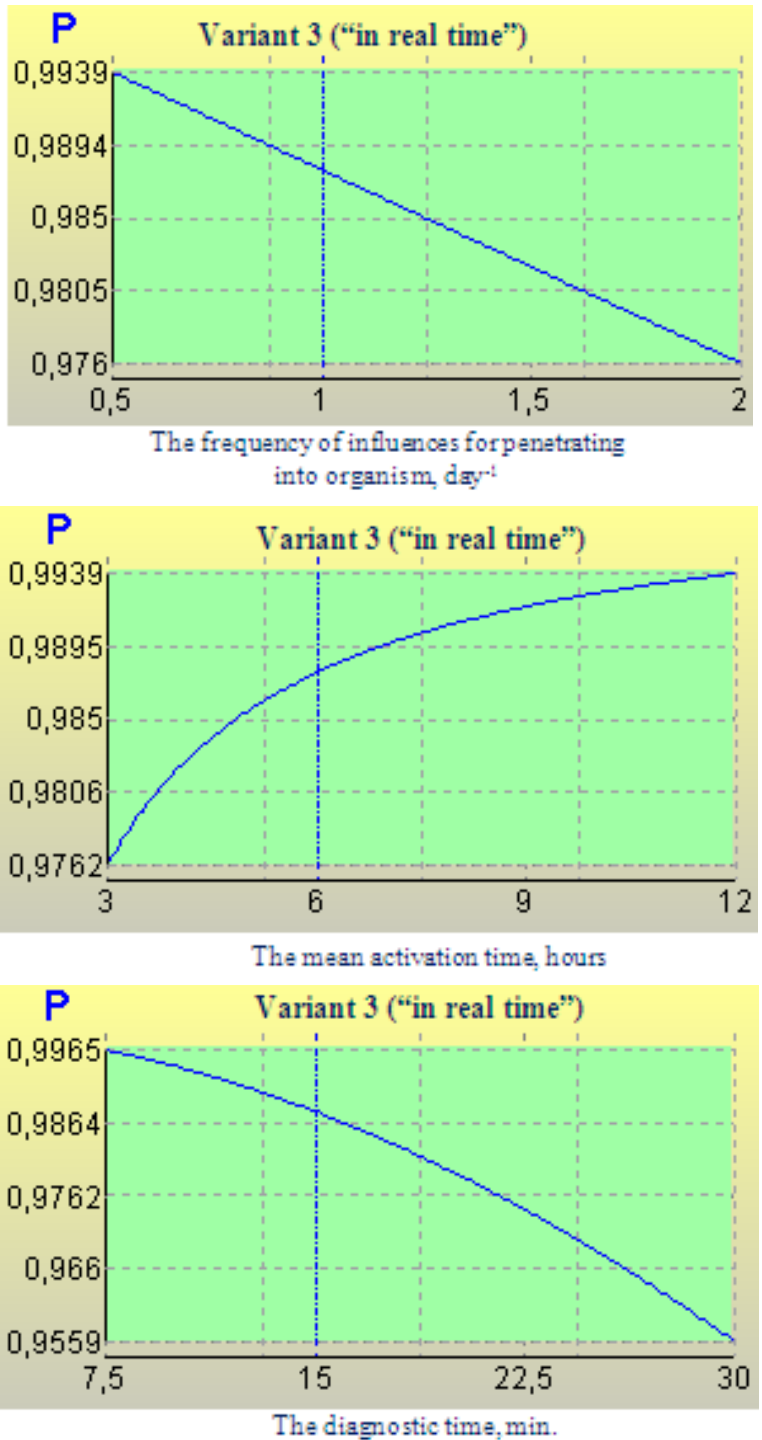

FIGURE IV. DEPENDENCE OF PROBABILITY TO KEEP

“ACCEPTABLE INTEGRITY” ON THE CHANGING INPUT DATA

However, thus it is necessary to go down at once on the earth - no normal person will execute pedantically every minute requirements from expert system for recovering his health, worsened for expired minute. Such system can simply "torture" the permanent recommendations to be in general case «healthy and rich». Moreover, universal medicines, reliably recovering reeled health for tens of minutes, are not invented yet. Besides, it is necessary to remain assumptions for modeling and to consider - any expert system can't work without errors! Nevertheless, various medical researches show, that potentially health reserves allow to live to the person much more than hundred years. This resume is also proved by the results of our probabilistic modeling.

\section{INSTEAD OF CONCLUSION}

The received results of the probabilistic analysis confirm quantitatively, that at the expense of continuous monitoring of organism conditions (including operative recovering of integrity to the acceptable level) a person in the near future can operate all life without any serious known diseases (about 90100 years with the probability 0.99 and more). I.e. the human dream about a life without illnesses can practically start to be carried out in the XXI-st century. Naturally, it will concern only the people, born healthy and caring about the health. This conclusion also is based on real possibility of the person to get in real time full and valid information about conditions of the organism and to manage rationally the own health.

\section{REFERENCES}

[1] A. Kostogryzov, G. Nistratov and A. Nistratov, "Some Applicable Methods to Analyze and Optimize System Processes in Quality Management”, Total Quality Management and Six Sigma, InTech, 2012, pp. 127-196, Available from: http://www.intechopen.com/books/totalquality-management-and-six-sigma/some-applicable-methods-toanalyze-and-optimize-system-processes-in-quality-management

[2] A. Kostogryzov, P. Stepanov, A. Nistratov, G. Nistratov, O. Atakishchev and V. Kiselev, Risks Prediction and Processes Optimization for Complex Systems on the Base of Probabilistic Modeling, Proceedings of the 2016 International Conference on Applied Mathematics, Simulation and Modelling (AMSM2016), May 28-29, 2016, Beijing, China, pp. 186-192

[3] A. Kostogryzov, P. Stepanov, L. Grigoriev, O. Atakishchev, A. Nistratov and G. Nistratov, Improvement of Existing Risks Control Concept for Complex Systems by the Automatic Combination and Generation of Probabilistic Models and Forming the Storehouse of Risks Predictions Knowledge, Proceedings of the 2nd International Conference on Applied Mathematics, Simulation and Modelling (AMSM 2017), August 6-7, Phuket, Thailand. DEStech Publications, Inc., pp. 279-283 